\title{
The Study of Second Language Acquisition Under Socio- Cultural Theory
}

\author{
Liang Aimin* \\ School of Foreign Languages, University of Jinan, Jinan City, China \\ *Corresponding author: sfl_liangam@ujn.edu.cn
}

Received April 26, 2013; Revised May 11, 2013; Accepted May 12, 2013

\begin{abstract}
Socio-Cultural Theory, based on Vygotskian thought, is a theory about the development of human cognitive and higher mental function. The theory specially emphasizes the integration of social, cultural and biological elements in learning processes and stresses the socio-cultural circumstances' central role in human's cognitive development. Second Language Acquisition is concerned with the process of how a new language other than the native language is acquired and how much this is affected by other disciplines, among which is SocioCultural Theory. This theory facilitates reflection on some of the problems on second language acquisition from a new perspective. In addition, this new perspective provides some pedagogical implications for foreign language teaching. This article makes attempts to elucidate Social-Cultural Theory's constructs, its influence on second language acquisition and the pedagogical implications for foreign language teaching.
\end{abstract}

Keywords: socio-cultural theory, second language acquisition, higher mental function, foreign language teaching

\section{Introduction}

Socio-Cultural Theory (SCT), based on Vygotskian thought, is a theory about the development of human cognitive and higher mental function. The theory argues that the development of human cognitive and higher mental function comes from social interactions and that through participation in social activities requiring cognitive and communicative functions, individuals are drawn into the use of these functions in ways that nurture and "scaffold" them. "From a social-cultural perspective, children's early language learning arises from processes of meaning-making in collaborative activity with other me mbers of a given culture" [18]. Lantolf and Thorne [16] defend that the principles of the SCT can also apply to Second Language Acquisition (SLA). They explain that "Learning is embedded within social events and occurring as an individual interacts with people, objects, and events in the environment" [6].

SLA is concerned with how individuals acquire a certain language other than the native language. SLA is defined by Grass and Selinker as "the study of how learners create a new language system with only limited exposure to a second language. It is the study of what is learned of a second language and what is not learned; it is the study of why most second language learners do not achieve the same degree of knowledge and proficiency in a second language as they do in their native language; it is also the study of why only some learners appear to achieve native like proficiency in more than one language" [11]. Throughout the few past decades, SLA has been discussed from different perspectives. One of these is behaviorism which proposes that language learning occurs through a series of stimuli and responses and that all learning is the establishment of habits as a result of reinforcement. Skinner [23] is one of the champions of this perspective, who holds that language is a verbal behavior, that is, that the production and comprehension of what is uttered is automatic. Thus, language learners can be made to automatically produce and comprehend language. For behaviorists, no learning occurs if there is no observable change in behavior. They mainly choose to ignore inaccessible mental processes and focus on observable behavior. During 1950s and 1960s, an alternative perspective 'cognitivism' appeared which originated from Chomsky's famous proposition of aLanguage Acquisition Devices (LAD) [5], in which he presented the nativist view to language learning. The cognitivists proposed that human beings are born with a genetic capability that predisposes them to the systematic perception of language around them, resulting in the construction of an internalized system of language. Therefore, SLA is a complete mental process [22]. Cognitivis $m$ offers a coherent understanding of the learning processes involved. It presents theoretical support for teaching practices and suggests a range of useful teaching strategies that encourage learning. However, cognitive perspective's focus on learning as an individual mental event ignores social processes and embodiment. Another view of language acquisition and development which is the focus of this article is the socio-cultural perspective which makes attempts to depict the interrelated cognitive and social characteristics in acquiring a second language. The socio-cultural perspective main ly comes fro $\mathrm{m}$ SCT, initially proposed by Vygotsky [26], but has been brought to the field of SLA by researchers including Lantolf \& Thorne [14] and Swain [11] etc. 


\section{The Constructs of Socio-Cultural Theory}

SCT is developed from the work of Vygotsky, his coworkers and succesors and this body of work is acknowledged in the term Cultural-Historical Activity Theory (CHAT). However, most research conducted on L2 learning within this general theoretical framework has used the term Socio-Cultural Theory (SCT), and for this reason we will use this term throughout the paper. SCT focuses on children cognitive development and specially emphasizes the integration of social, cultural and biological elements and believes that socio-cultural circumstances play a central role in human's cognitive development and that the process of the development higher mental functionioning is the one by which people internalize or regulate what they learn from social activities through the mediation of symbolic tools (languages) and by going through the zone of proximal development, and during this period, language develops from social speech to private speech and then finally to inner speech or verbal thought. Therefore, the central constructs of the theory are mediation, regulation, internalization, the zone of proximal development, verbal thought and activity theory.

\subsection{Mediation}

Mediation is the principle construct that unites all varieties of SCT and is rooted in the observation that humans do not act directly on the world-rather their cognitive and material activities are mediated by symbolic tools as well as by physical tools. While physical tools are outwardly directed, symbolic tools are inwardly or cognitively directed. Just as physical tools serve as auxiliary means to enhance the ability to control and change the physical world, symbolic tools serve as an auxiliary means to control and reorganize our biologically endowed psychological processes [2]. Language is the most pervasive and powerful symbolic tool (cultural artifacts) that humans possess to mediate their connection to the world, to each other, and to themselves [3]. That is, Language imbues humans with the capacity to free themselves from the circumstances of their immediate environment and enables them to talk and thin $\mathrm{k}$ about entities and events that are displaced in both time and space, including those events and entities that do not yet exist in the real world. In sum, human mental functioning is fundamentally a mediated process that is organized by cultural artifacts, activities, and concepts [9].

\subsection{Regulation}

The original meaning of regulation is the controlling of an activity or process, usually by means of rules. In SCT, regulation is one form of mediation referring to children's capacity to regulate their own activity through linguistic means by participating in activities (mental and physical) in which their activity is initially subordinated, or regulated by others. The process of developing selfregulation moves through three general stages. The first stage, known as object-regulation, is that children are often controlled by or by using objects in their environment in order to think. The second stage, termed other-regulation, includes implicit and explicit mediation (involving varying levels of assistance, direction, and what is sometimes described as scaffolding) by parents, siblings, peers, coaches, teachers, and so on. The final stage, termed self-regulation, refers to the ability to accomplish activities with minimal or no external support. Self-regulation is made possible through internalization.

\subsection{Inte rnalization}

Internalization refers to the process of making what was once external assistance a resource that is internally available to the individual [8]. Vygotsky captured the interconnection established by internalization in his general law of genetic development: Every psychological function appears twice, first between people on the interpsychological plane and then within the individual on the intra-psychological plane [27]. Internalization is a negotiated process that reorganizes the relationship of the individual to her or his social environment and generally carries it into future performance. Internalization accounts for the organic connection between social communication and mental activity and is the mechanism through which we gain control over our brains, the biological organ of thinking. Imitation is regarded as the best approach by which internalization is realized. However, Imitation here is different from the concept in behaviorism which only copies or imitates others' behaviors passively but involves goal directed cognitive activities that can result in the creative and active transformations from interpsychological plane to intra-psychological plane. Just as Vygotsky states that imitation is "the source of instruction's influence on development" [27].

\subsection{The Zone of Proximal Development}

The Zone of Proximal Development (ZPD) originated from Vygotsky's genetic law of cultural developments [4], in which Vygotsky put forward child's two development levels. The first is the actual developmental level, that is, the level of skill reached by the child working independently. The second is the future development level, that is, the level of potential skill that the child is able to reach with the assistance of a more capable instructor. Vygotsky viewed the ZPD as a way to better explain the relation between children's learning and cognitive development. He believed that learning always precedes development in the ZPD. In other words, through the assistance of a more capable person, a child is able to learn skills or aspects of a skill that go beyond the child's actual developmental [4]. Therefore, development follows the child's potential to learn. In this sense, the ZPD provides a prospective view of cognitive development, as opposed to a retrospective view that characterizes development in terms of a child's independent capabilities.

\subsection{Verbal Thought}

Vygotsky's other vital contribution concerns the interrelationship of language development and thought which was explored in his book Thought and Language [18]. The famous linguist Saussure distinguished between speech and language. He pointed that language is a symbol system to express one's thoughts and ideas and that speech is the spoken production of language and the process through which sounds are produced. Language 
belongs to society and is a psychological and social phenomenon while speech belongs to individuals and is a psychological and physical phenomenon [7]. Vygotsky agrees with Saussure's distinction between language and speech. He also believed that language and speech had close connections so that they cannot be separated, which means that in Socio-Cultural Theory, language and speech have almost the same connotation. In language development, Vygotsky believed that there were three stages. The first stage is called Social Speech (or External Speech). In this stage, a child uses speech to control the behavior of others and to express simple thoughts and emotions such as crying, laughter and shouting. The second stage, named Egocentric Speech or Private Speech, is typically the type of speech found in three to seven year -old children. It serves as a bridge between the primitive and highly public social speech of the first stage and the more sophisticated and inner speech. In this stage, children often talk to themselves, regardless of someone listening to them. They think out loud in an attempt to guide their own behavior. They may speak about what they are doing as they do it. They reason that language must be spoken if it is to direct their behavior. The third stage is Inner Speech. This is the type of speech used by older children and adults. This type of speech allows us to direct our thinking and behavior. Once one has reached this final stage they are able to engage in all forms of higher mental functions. This stage is also called verbal thought stage in which speech and thinking are connected together.

\subsection{Activity Theory}

Activity Theory, created by Vygotsky and later developed into an independent theory system by one of his students, Leontev, deals with the unified nature of human behavior, which is considered to be the result of the integration of social and cultural mediations. According to Vygotsky, activity can be regarded as a framework in which mind is observed and studied. That is to say, mind is the subject studied in psychology, and it can be observed or displayed through people's activities. Leontev also points out that activity includes three levels --- activity, action, and operations, corresponding with the three concepts---motive, goal and condition. Activity supplies social-environments with clear goals, motive displays the reasons why something has happened and action is the exact process to show how the activity is operated [22]. Lauria [17] believes that mind is not the result of the activity occurring in the brain but a functional system shaped as the brain's electro-chemical processes come under control of our cultural artifacts, the most important of which is language. In line with Lauria, Lantolf [13] also suggests that an activity is motivated by a need which might be either social or biological, like the need to become literate and the need for food. Therefore, it is believed that motives emerge through certain activities which are goal directed and are accomplished under certain conditions.

\section{Socio-Cultural Theory and SLA}

As for SLA, SCT's ideology is quite different from that of the behavioris $m$ and cognitivis $m$. In behaviorism it is implied that language learning occurs when individuals provide conditioned responses to stimuli and that language learning is a process of habit formation. By contrast cognitivism expects more cognitive participation of language learners in the process of learning and contends that learners make use of their mental processes. However, SCT presented another ideology of learning, which appeared in the field of learning with two perspectives: cognitive and social. Grounded upon SCT, social interaction and cooperative learning are paramount in constructing both cognitive and emotional images of reality. Human learning is a continuous reciprocal interaction of cognitive, behavioral and environmental factors [9]. Therefore, SCT provides a new perspective on the process of SLA, in which learners are encouraged or required to thin $\mathrm{k}$ as well as speak in the target language, that is to say, language and thought should be closely connected with each other. The root for this connection lies in social communication activities.

\subsection{Mediation and SLA}

As stated above, language learning is a socially mediated process. Mediation is a fundamental principle and language is a cultural artifact that mediates social and psychological activities. second language acquisition is a process of mediation in which there are three kinds of mediation. They are other-mediation, self-mediation and the mediation of cultural artifacts [2]. Other- mediation refers to the mediation between experts and novices, the mediation between the more capable peers to the less capable ones. According to Theory of ZPD, the further development in the zone of proximal development is achieved through the cooperation of experts and novices or the cooperation of peers [27]. Therefore, in second language learning, we should try to solve the problems how to supply students with appropriate scaffoldings and supports. Self -mediation concerns two main concepts, that is, private speech and gestures. Private speech or "self-talk" is observed speech spoken to oneself for communication, self-guidance, and self-regulation of behavior: In second language acquisition, private speech has three different kinds of functions, that is, metcognition function, practice function and internalization function [1]. That means that in language acquisition, individuals can develop their cognitive function, improve their capability of using the language and internalize it by speaking to themselves. Gestures are regarded as the other form of private speech, which can augment the oral private speech in face- to- face conversation or in telephone calls. The mediation of cultural artifacts is also very important which concerns the socio-cultural environment and first language. In second language acquisition, individuals should try to apply the sociocultural environment and first language to acquire the target language.

\subsection{Inte rnalization and SLA}

The concept of internalization is inseparable from scaffolding and ZPD. Lantolf and Thorne define it as the "means of developing the capacity to perform complex cognitive and motor functions with increasingly less reliance on externally provided mediation" [14]. Lantolf [15] claimed that it is through internalization of the zone of proximal development that the activities between 
people and cultural artifacts transform into the inner activities of our brains. As stated previously, imitation is the most effective method to promote internalization in language acquisition. But imitation linked to internalization is not the imitative process occurring immed iately after a given pattern appears in the learner's linguistic environment. Rather, imitation can occur with a delay of a day or more. Deferred imitation permits children to analy ze language "off-line" and is considered a continuum between imitation and spontaneous language production because deferred imitation serving as "essential build ing blocks for spontaneous speech" [16]. Experts discovered the examples of both delayed and immediate imitation produced by L2 children as they engaged in various education and play activities in their classroom. Internalization in second language classrooms also suggests the enhancement of interactions among the learners. Following the significance of interaction among the learners, it is also vital that teachers realize that the role of expert is not limited to that of a teacher, but it can also be applied to those learners who have internalized an aspect of the language.

\subsection{Verbal Thought and SLA}

In SCT, language acquisition concerns language function development, mental function development and the combination of language and thought. Generally speaking, it includes the process that the low level external or social speech develops into the highest level inner speech or verbal thought.

Just as stated before, language acquisition should have at least three basic elements, that is, language function development, mental function development and the combination of language and thought. Firstly, people should have the elementary level of language function and mental function which come from the phylogeny development and the neural system. Secondly, language and thought can be combined in a certain condition. At this time, speech is mediated by thought and thought is mediated by speech. And both speech and thought are combined together and develop into a kind of higher mental function. The combination here is completed by participation in social co mmunication and social activities. Therefore, language acquisition, a higher level inner speech development, should come from the social communication and social activities.

SCT also strongly claims that the process of language acquisition is the process in which an individual's external speech is gradually internalized and combined with thought by means of communicative activities. The detailed steps are from External Speech (without thought) to Egocentric Speech (beginning to comb ine with thought) and to Inner Speech (becoming verbal thought). The final results of second language acquisitions are that people are able to think about things with the target language and then language and thought are combined together finally becoming verbal thought. Sometimes, the relationship between speech and thinking can be expressed by two intersecting circles. The shared area is called verbal thought.

\subsection{Activity Theory and SLA}

To find out how activity theory brings new insights for language development and second language acquisitions, several studies have been conducted, Such as, [12,20]. Coghlan and Duff [25] examined a task-based performance from the activity theory perspective. They contended that scholars always view tasks as being scientifically controllable and measurable, yet they expressed their doubt about the constant nature of a task and argued that tasks are quite variable. They contended that different people react differently to the same task. They proposed an active role for the learners and maintained that learners are active agents who, according to their own goals, give specific directions to the activities and even different times and conditions have different impacts on heir performance on the same task. "The activity becomes unique for each learner because it emerges from the interaction between the speakers and the interviewer, the setting, the subjects' motivations and histories. Therefore, it cannot be separated from its socialcultural context, from which it is co-constructed" [25]. Gillette [12] also probed into the issue of individual differences through a series of case studies in the activity of language acquisition and proposed that the learning outcome is closely linked to the learners' motives and that their motives are socially and historically constructed, for example some learners wish to acquire a second language as much as possible while others may acquire it just to meet certain purposes. She also highlighted the fact that the use value they ascribe to language arises from contact with the world, for example while efficient learners travel a lot, less efficient learners may not. In other words, she attributed the degree of success in the language learning process to the learners' motive, his/her goal and value, which are socially and historically constructed. In line with Gillette, Wen [21] also views language learning through the lens of activity theory and believes that choosing certain tasks for language teaching is under the influence of the learners' motives, goals and condition of learning.

\section{Pedagogical Implications for Foreign Language Teaching}

SCT compels us to study some subjects of second language acquisition from a new perspective which can be distinguished from other theories. In addition, this new perspective also provides numerous pedagogical implications for foreign language teaching. One common belief within the framework of SCT is the notion that learning occurs effectively when students interact with one another in foreign language classrooms. Unlike the traditional assessment which focuses on the final product of what learners have achieved, Dynamic Assessment (DA) seeks to find out how internalization takes place when assistance is provided.

\subsection{Teaching Through Interaction}

The socio-cultural theorists who work primarily within second language acquisition framework assume that a great deal of language learning takes place through social interaction, at least in part because interlocutors adjust their speech to make it more accessible to learners. The essence of language is to be able to communicate one's thoughts and feelings to another person. This concept of 
communication is one of the foundations of SCT in language learning, which is one of the second language acquisition theory modules. SCT believes that language can be acquired easily by allowing the students to socialize and interact either with other learners or with the speakers of the language they are learning. The interaction should also be within the context of the language being learned. Ideally, SCT suggests that the best way to acquire a language is to learn it from the place it is being used and to interact with native speakers. In the context of the classroom, SCT in second language acquisition can be practiced through social activities that simulate the cultural context of the language. Aside from the classic role playing, here are some activities for strengthening the communication skills of second language learners based on SCT.

Firstly, Story Telling. Shared story telling is a typical interactive activity in which the teacher will present a set of related pictures that tells a story. In groups of 4 to 5 , the learners would have to construct a story by describing what they see in the pictures. Each member of the group must have an assigned picture that he will connect to other pictures. Depending on their level, they can add dialogues and characters. This activity can also be used in retelling a story taken up in class.

Secondly, Think-Aloud. Give the learners a situation in which they have to make decisions or choose options. While they are deciding on what to do with the situation given to them, they spontaneously say out loud the things that go on in their mind. They must be able to have a resolution at the end. Allot a specific period of time for this activity. For example, a learner must be able to decide within two minutes on whether he will attend a party of a person he doesn't like. The situations must be realis tic and within the experience of the learners. The purpose of this activity is for the learners to think in the language they are acquiring and make it automatic to them. This will also help them see that communication is not only with other people but also with oneself.

Thirdly, Language Date. Language date refers to an activity to arrange a day in which students can meet up with native speakers who will serve as their company for the day. The learner and the native speaker must arrange some activities they can do together like dining out, shopping, playing some sports. The native speaker must not be able to understand the learner's native language. This way, the learner will be forced to speak the language he/ she is learning. At the same time, this will also expose the students to the use of language in an authentic situation.

\subsection{Dynamic Assessment}

The practical application of ZPD can be shown in Dynamic Assessment (DA) which aims to assess an individual's learning potential. To Vygotsky, it is not enough to know what an individual can do alone without assistance, as reflected in traditional approaches to testing; it is necessary to discover what the person can do through scaffolding (i.e., instruction, peer supports or learn ing aids etc..), because it portrays what the person will eventually be able to do when that help has been internalized. In DA, we can see that Vygotsky laid special emphasis on a kind of instruction which was aimed at the future, at what the person cannot yet do at present. In fact, DA is an interactive approach to psychological assessment that embeds intervention within the assessment procedure. And the most important two characteristics of it are: 1) inseparability of assessment and instruction, 2) construction of future development. Thus DA is a futurein-the-making model where assessment and instruction are dialectically integrated as the means to move towards an always emergent future rather than a fixed end-point.

Dynamic Assessment procedural framework is a practicable approach which can be applied into process writing to dig the dynamic essence of process writing fully and facilitate the cognitive development of English learners. The procedural framework of DA is in fact a chain of pretest-teach-posttest. Before pretest, the teacher should define the aim, which shows what students should be capable of doing. Then it is to pretest, in which students try to finish the given task, and the teacher observes carefully and finds problems. The third step is to teach, in which the teacher designs some mediation activities aiming to solve the existing problems in students' performance. The last is to posttest, in which the students are asked to try the task again based on the teacher's intervention, and the teacher adopts appropriate method to evaluate students' performance.

Combining procedural framework of DA with features of EFL writing, we can design a practical DA framework for EFL process writing. The dynamic assessment framework, exactly, dynamic mediation process, emphasizes the easily-neglected, but most important three stages: 1) topic-choice stage, 2) idea generation \& structuring stage, and 3) macro-revising stage, though other stages such as drafting, editing are also included in the writing process. Given the length of this paper, the details of the three stages will not be discussed here. In each of the above stages, DA components can be designed as three steps: 1) pre-task, 2) mediation, and 3) post-task. Pre-task, $\operatorname{task}(\mathrm{s})$ done before mediation, is expected to create learners' ZPD, and can increase their sensitivity to assistance and willingness to get assistance. By giving mediation to learners in the form of either dialogues between teacher and students, or mediational tools (guidelines, samples, reading materials etc.), their internal developmental processes would be awakened. Post-task, the imitation of externally obtained skills or knowledge, can contribute to an obvious improvement, which subsequently would become part of learners' independent developmental ability, in learners' work. In the processoriented instruction, the effort made for promoting writing is not a static, separate and unilateral endeavor of either the teacher or the learner; in contrast, it is a dynamic, continuous and mutual effort.

Unlike other assessments, which set their objective as evaluating the level of students or providing feedback for their study, the ultimate goal of Dynamic Assessment is promoting development. By interpreting the potential of learners (pre-task), assistance is made via the interaction between mediators and learners aided by language (dialogue) or other mediational tools (mediation). Since the mediation is made in the Zone of Proximal Development of learners, remarkable progress is likely to occur. 


\section{Conclusions}

Second language acquisition has undergone major changes during recent decades. Different theoretical perspectives made language teachers and curriculum developers behave and think differently as to how language learners should learn a second language. Vygotsky's SCT holds that social interaction and cooperative learning are paramount in constructing both cognitive and emotional images of reality just as Vygotsky claimed that "children's thinking and meaningmaking is socially constructed and emerges out of their social interactions with their environment" $[25,26]$. The theoris ts of SCT contend that learning occurs as a result of shared experiences in a range of social settings. Another common belief within the frame work of SCT is the notion that learning occurs effectively when students interact with one another in foreign language classrooms, yet SCT should not be viewed as a theory just for learners. We must be well aware that the knowledge of SCT can also be useful for teachers to discover and create ways to set up tasks and activities which can allow for the facilitation of language learning.

\section{References}

[1] Brown, H. D. Principles of language learning and teaching, Pearson Education Inc. New York 2007,30-36.

[2] Bruner, J. Actual minds, possible worlds, Harvard University Press. Massachusetts, 1986,45-61.

[3] Centeno-Cortés, B.. Private speech in the second language classroom: Its role in intemalization and its link to social production. Unpublished doctoral dissert ation, Pennsylvania State University. University Park, 2003,45-60.

[4] Chaiklin, S. The zone of proximal development in Vygotsky's analysis of learning and instruction. In A. Kozulin, B. Gindis, V. Ageyev, \& S. Miller (Eds.), Vygotsky's Educational Theory in Cultural Context. Cambridge University Press, Cambridge, 2003, 39-64.

[5] Chomsky, N. Language and mind, Harcourt Brace Jovanovich, New York, NY, 1968,78-94.

[6] Cook, V. Second language learning and language teaching, Hodder Education. London, 2008, 54-60.

[7] Davies, A. An introduction to applied linguistics: From practice to theory, Edinburgh University Press, Edinburgh, 2007, 23-34.

[8] Donato, R. Collective scaffolding in second language learning. In: J. P. Lantolf and G. Appel. (eds.), Vygostskian appraaches to second language research. Ablex Publishing Corporation, N.J. 1994, 33-56.

[9] Ehrich, J. F. Vygotskian inner speech and the reading process. Australian Journal of Educational \& Developmental Psychology, 6(3).12-25. Jun. 2006.

[10] Ellis, R. Task-based research and language pedagogy. Language Teaching Research, 6(3) .193-220. Jun.2000.

[11] Gass, S. M., \& Selinker, L. Second language acquisition, Taylor \& Francis, Routledge, Oxon, 2008, 30-34.

[12] Gillette, B. The role of learner goals in L2 success: Sociocultural theory and children with special needs. In:J.P. Lantolf \& G. Appel. (eds.), Vygotskian approaches to second language research, Norwood, NJ: Ablex, 1994, 195-210.

[13] Lantolf, J. P . Sociocultural theory and second language learning, Oxford University Press, Oxford, 2000, 34-35.

[14] Lantolf, J. P. \& Thorne, S. L Socio-cultural theory and the genesis of second language development, Oxford University Press, Oxford 2006, 23-24.

[15] Lantolf, J.P.Socio-cultural theory and second language development:State-of-the-art [J]. Studies in Second Language Acquisition, 54 (28). 67-109. Dce. 2006.

[16] Lantolf, P. J. Sociocultural Theory: A unified approach to L2 learning and teaching .In J. Cummins \& C. Davison.(eds.), Intemational handbook of English language teaching, Springer Science Business Media, LLC, NY, 2007, 693-701.

[17] Lauria,A.R. The making of mind. A personal account of Soviet psychology. Harvard University Press, Cambridge, MA,1979,4550.

[18] Liwei. Thought and language, Beijing University Press, Beijing, 2010, 10-11.

[19] Mitchell, R. Myles, F. Second language learning theories, Arnold, London, 2004, 4-6.

[20] Parks, S. Same task, different activities: Issues of investment, identity and use of strategy. TESL Canada Journal, 17(2). 64-89. Feb.2000.

[21] Ratner, C. Cultural psychology:theory and method, Kluwer/Plenum, New York, 2002,67-73.

[22] Roebuch, R. Reading and recall in L1 and L2: a sociocultural approach, Ablex Publishing Corporation, Stamford, 1998,55-60.

[23] Skinner, B.F. Verbal behavior. Appleton-Century-Crofts, New York, 1957, 24-30.

[24] Swain,M. The output hypothesis and beyond: mediating acquisition through collaborative dialogue. In Lantolf,J.P.(ED). Sociocultural Theory and Second Language Learning. Oxford University Press, Oxford, 2000, 97-114.

[25] Wen,W. Activity theory and second language acquisition. Sino-US English Teaching, 5(5), May 2008.[Online]. Available:http://www.linguist.org.cn/doc/su200805/su20080504.p df. (accessed 24/6/2011).

[26] Vygotsky, L. Mind in society: The development of higher psychological processes, Harvard University Press, Cambridge, MA, 1978, 56-58.

[27] Vygotsky, L.S.. Problems of general psychology, In R. Reiber \& A. Carton (Eds.) The Collected Works of L. S. Vygotsky, Plenum Press, New York, 1987, 2. 